\title{
Research on Land Rearrangement Zoning of Country Area
}

\author{
Ruixuan Yang \\ School of Land Science and Technology, China \\ University of Geosciences \\ Beijing, China \\ dingdangyang@163.coml
}

\author{
Jinman Wang*,1,2, a Chiqu Ye ${ }^{1, b}$ \\ ${ }^{1}$ School of Land Science and Technology, China University of \\ Geosciences \\ ${ }^{2}$ Key Laboratory of Land Regulation Ministry of Land and \\ Resources \\ Beijing, China \\ awangjinman2002@163.com, badom24k@163.com
}

\begin{abstract}
Land rearrangement zoning is to create its direction and key aspect, operate different administration and make land rearrangement measures that in keeping with the real conditions of local area. Huairou district of Beijing was taken for instances, taking administrative villages as zoning unites to get 4 indexes and 10 factors for analyzing based on natural and socio - economic conditions by using comprehensive index value method. Huairou district was divided into 5 areas: plain-agricultural area, hilly-agricultural area, urban-developing area, ecological-protecting area, tourist-developing area after comprehensive analyzing. Direction and key aspects of land rearrangement in each zone were confirmed. This zoning can provide land rearrangement measures targeted in each zone. ${ }^{1}$
\end{abstract}

Key words_Land rearrangement; zoning; evaluation; Beijing

\section{INTRODUCTION}

Land rearrangement zoning must be put into effect to clear and define its types and directions, operating different administration in each zone ${ }^{[1]}$. It is based on analyzing similarities and differences in utilization conditions, structures, problems, way to land rearrangement and development direction of land resource, and then, zoning the same type of land rearrangement in space. It also indicates direction and latent capacity of land rearrangement and suggests basic means and measures to develop, use, consolidate, rehabilitate and protect land resource. Land rearrangement zoning has fundamental significance in fields such as classification management of land resource ${ }^{[3-5]}$, and it is an important mean to ensure the effect of land rearrangement and an effective way to realize regional sustainable development ${ }^{[6]}$.

Huairou district is in hilly areas and it has only a few plain in south. The hilly area in north is primarily forest land while the plain area in the south is primarily arable land and construction land. Huairou district is an important ecological reserve and tourist area. Its various natural condition, ngement is adjustments and reforms of the president land use state ${ }^{[2]}$. Land rearrangement zoning confirms current situation, features, experiences and demand of land rearrangement according to its differences, and coordinates

\footnotetext{
* Corresponding author
}

works, confirms direction and key aspects and operate different administration in all areas.

\section{ZONING METHODS}

Too many methods were used in former zoning studies. For example, it was analyzed from administrative districts and physical geography unites in agricultural regionalization and land-use regionalization ${ }^{[7]}$, a combined method of spatial overlay and principal factor method was used in land reclamation zoning ${ }^{[8]}$, Yuqi Lu et al innovated index discriminance and index superposition in spatial development regionalization ${ }^{[9]}$.

We believe that some attributes like soil type and land use type are homogeneous attributes while some attributes like reclamation condition and urban development type are heterogeneity, we called it function attribute. The areas of agricultural regionalization and land-use regionalization are homogeneous regions, the variability of area could be regionalized by some factors easily. But though areas of land reclamation zoning and urban development regionalization have homogeneous attributes, their function attribute are more obvious when regionalization so they can't use method of land-use regionalization simply. Similar to them, the direction of land rearrangement is the most important target in land rearrangement zoning and it is heterogeneity. So, comprehensive index value method was used based on the methods of land reclamation zoning and spatial development regionalization in this study.

\section{A. Comprehensive index value method}

Comprehensive index value method is combined qualitative analysis and quantitative analysis. Qualitative analysis is more infulenced by subjective factor. Quantitative analysis set up a zoning process using zoning index system for land rearrangement quantization, and partly conquered subjective factors, but it also could be affected by availability of indexes and scientificity of indexes selecting. So, combining qualitative analysis and quantitative analysis is a normal method to zoning.

\section{B. Calculating comprehensive index value}

The indexes sum method is used in this study. Multiplying the weight of evaluation factors of each evaluation unit and its grade, then plus the results, and the 
final result is comprehensive index value of each evaluation unite. This value is called comprehensive index value. The calculation model is showed as Eq. 1:

$$
G_{i}=\sum_{i=1}^{n} p_{i j} x_{i j}
$$

Where : $\mathrm{G}$ - evaluation unit ; $\mathrm{P}$-weight of evaluation factor ; $\mathrm{x}$-grade of evaluation factor ; $\mathrm{i}$ - sequence number of evaluation unit ; $\mathrm{j}$-sequence number of evaluation factor.

\section{THE PROCESS OF LAND REARRANGEMENT ZONING}

\section{A. Dividing evaluation units}

Choosing all of land in Huairou district as object of evaluation and all administrative villages as evaluation unites. 288 evaluation units are divided.

\section{B. Construction of evaluation index system}

\section{1) Selection of evaluation indexes and factors}

Huairou district is eco-conserving division in Major function Oriented Zoning in Beijing and it also an important tourist area. 4 indexes and 10 factors were got by analyzing its natural and socio - economic conditions (Table 1).

\section{2) Assignment of evaluation factors}

The value of arable area, basic farmland area, agricultural population, construction land area, non-agricultural population, quantity of enterprises, forestland area and river area can be counted directly. The primary data of geomorphic type structure and whether scenic site is planed was not quantifiabledata, but they could be quantized with different class rating.

\section{3) Determining weight}

Expert evaluation method is chosen.

\section{4) Determination of classification standards}

Critical values were determined and assigned different grade with different class ranting. There were 4 evaluation classes, its grades was $100,80,60$, and 40 from high to low.

\section{Classification of evaluation indexes}

Every index had 4 comprehensive index values that calculated by using indexes sum method. I was the highest class while IV was the lowest class. Classification standards are in table 2 .

\section{Classification of evaluation indexes}

All classification results of 4 indexes were showed in figure 1. This result could reveal the difference of natural, social and agricultural development in Huairou district objectively.

\section{E. Land rearrangement zoning}

Every evaluation unites had 4 comprehensive index value based on classification. Let the index which had the highest value as the zone represented by this index. For example, urban construction class of Dongguan valley in Huairou town was the highest class of I, then, Dongguan valley in Huairou town was belong to urban construction zone. Agricultural development was the priority and urban construction was secondary in plain area while ecological protection was the priority in hilly area when any evaluation unites had the two or three same classes. Tourism development was the priority if ecological protection class was the same with tourism development class according to integrated land-use planning 。 For example, Lilianghe valley of Miaocheng town was zoned in agricultural development zone even though both of its agricultural development class and urban construction class were both the highest. Tianxianyu valley was zoned in tourism development zone according to integrated land-use planning even though both of its ecological protection class and tourism development class were both the highest.

The primary task of this land rearrangement planning is agriculture land consolidation focusing on constructing large-scale basic farmland that could ensure stable yields despite drought or waterlogging. There is more agriculture land in Huairou district and they are distributed in hilly area and plain area with different slop. The slop of agriculture land in plain area are mostly within $0^{\circ}-6^{\circ}$ and in plain area are mostly higher than $6^{\circ}$. Slop is an extremely important limit factor for agriculture land consolidation, and different consolidation measures should be taken in area with different slop. So, agricultural development zoned was divided into two sub-zones: plain agriculture was within the slop of $0^{\circ}-6^{\circ}$ and hilly agriculture zone with slop of high than $6^{\circ}$.

Huairou district were divided into 5 land rearrangement zones: plain agriculture, hilly agriculture zone, urban construction zone, ecological protection zone, tourism development zone (Fig. 2).

Table 1 Grade standards of main evaluation indexes and factors

\begin{tabular}{|c|c|c|c|c|c|c|}
\hline Index & Factor & Weight & 100 & 80 & 60 & 40 \\
\hline \multirow{3}{*}{$\begin{array}{c}\text { agricultural } \\
\text { development level }\end{array}$} & arable area $(\%)$ & 0.5 & $>0.3$ & $0.2 \sim 0.3$ & $0.05 \sim 0.2$ & $<0.05$ \\
\hline & basic farmland area $(\%)$ & 0.3 & $>0.5$ & $0.3 \sim 0.5$ & $0.1 \sim 0.3$ & $<0.1$ \\
\hline & agricultural population(\%) & 0.2 & $>0.9$ & $0.8 \sim 0.9$ & $0.7 \sim 0.8$ & $<0.7$ \\
\hline \multirow{3}{*}{$\begin{array}{c}\text { urban construction } \\
\text { level }\end{array}$} & construction land area $(\%)$ & 0.5 & $>0.4$ & $0.2 \sim 0.4$ & $0.1 \sim 0.2$ & $<0.1$ \\
\hline & non-agricultural population & 0.2 & $>0.15$ & $0.1 \sim 0.15$ & $0.06 \sim 0.1$ & $<0.06$ \\
\hline & quantity of enterprises & 0.3 & $<1$ & $1-3$ & $3-5$ & $>5$ \\
\hline \multirow{2}{*}{$\begin{array}{c}\text { ecological protection } \\
\text { level }\end{array}$} & geomorphic type structure & 0.5 & hills & hills >plains & plains $>$ hills & plains \\
\hline & forestland area & 0.5 & $>0.8$ & $0.5 \sim 0.8$ & $0.2 \sim 0.5$ & $<0.2$ \\
\hline \multirow{2}{*}{$\begin{array}{c}\text { tourism } \\
\text { development level }\end{array}$} & river $\operatorname{area}(\%)$ & 0.3 & $<1 \%$ & $1 \% \sim 5 \%$ & $5 \% \sim 10 \%$ & $>10 \%$ \\
\hline & whether scenic site is planed & 0.7 & Yes & - - & - - & No \\
\hline
\end{tabular}


Table 2 Index classification standards

\begin{tabular}{|c|c|c|c|}
\hline Index class & I & II & IV \\
\hline agricultural development class & $>80$ & $61-80$ & $51-60$ \\
\hline urban construction class & $>80$ & $66-80$ & $51-65$ \\
\hline ecological protection class & $>90$ & $71-90$ & $51-70$ \\
\hline tourism development class & $>80$ & $61-80$ & $<1-60$ \\
\hline
\end{tabular}

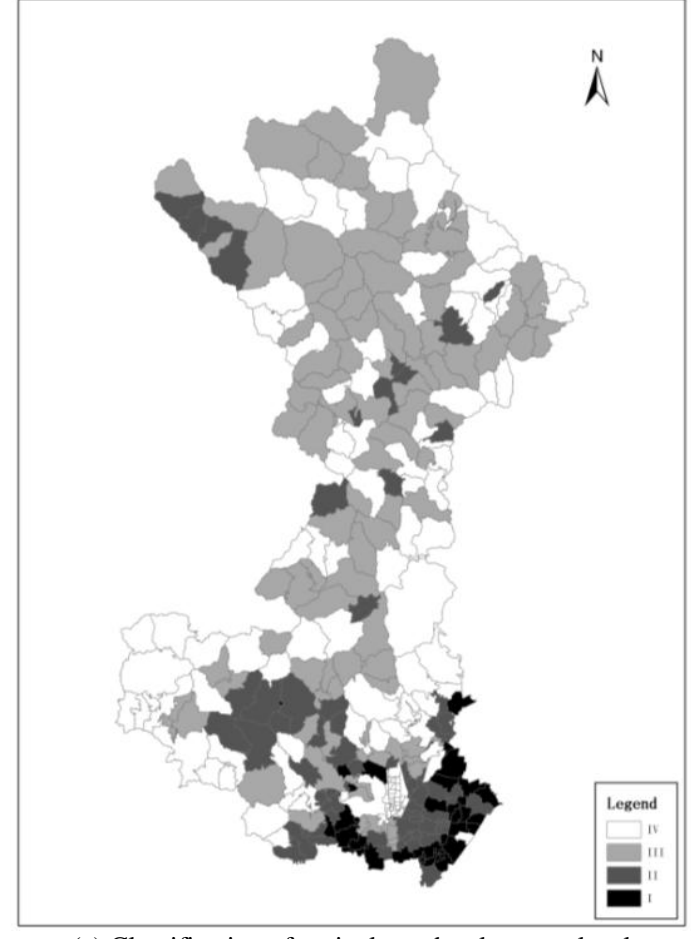

(a) Classification of agriculture development level

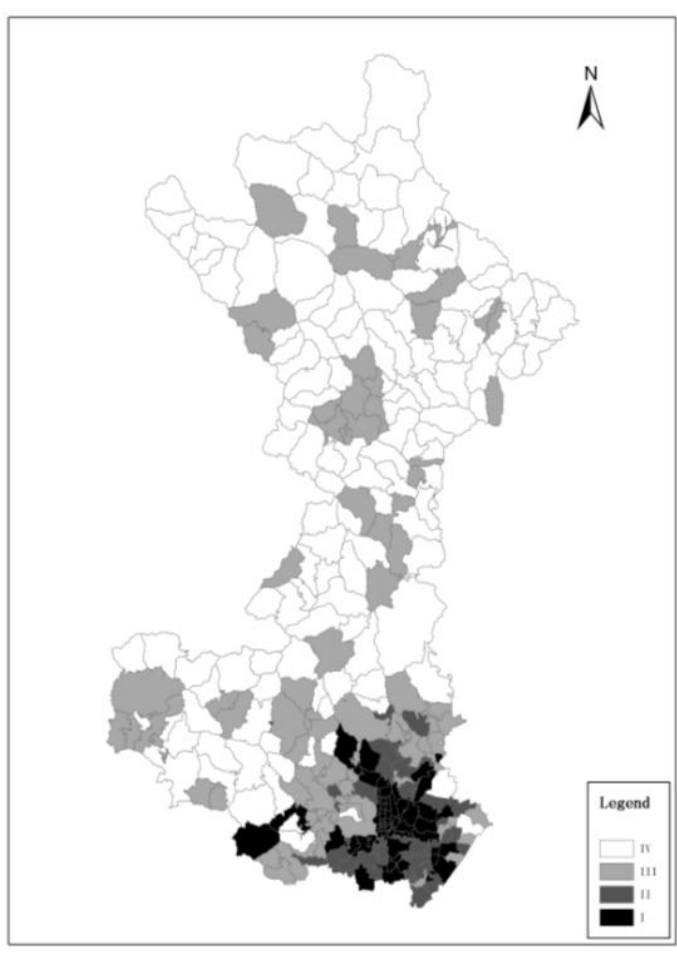

(b) Classification of urban construction level

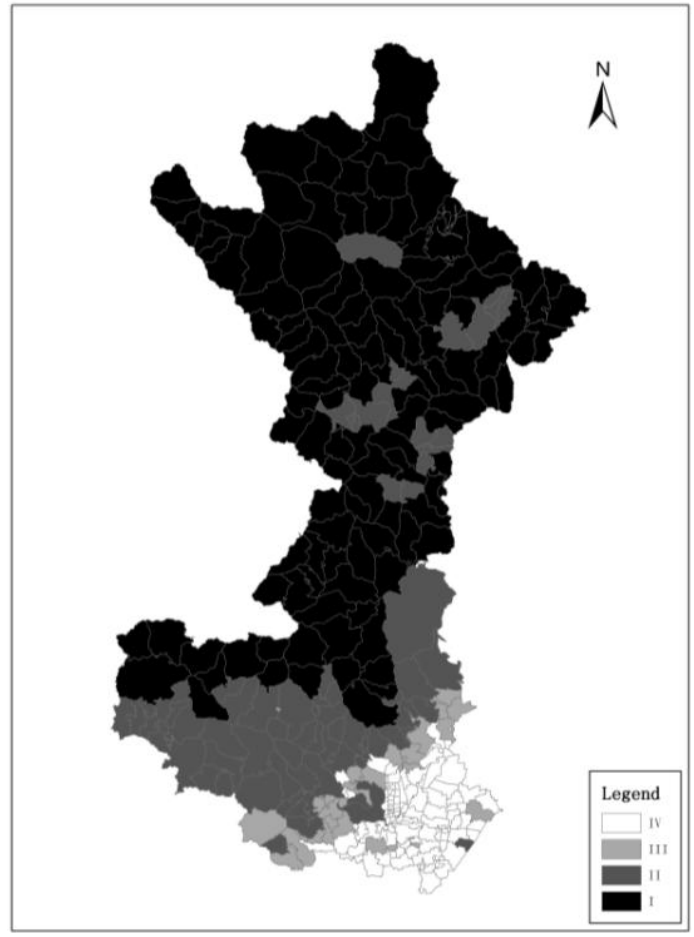

(c) Classification of ecological protection level

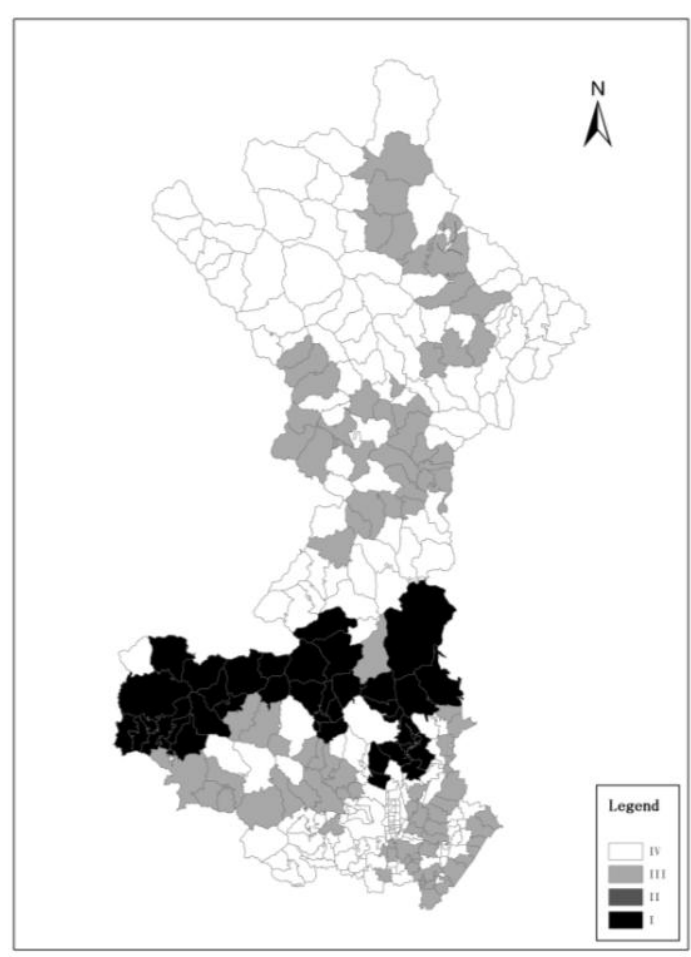

(d)Classification of tourism development

Fig. 1. Classification of 4indexes level in Huairou district 


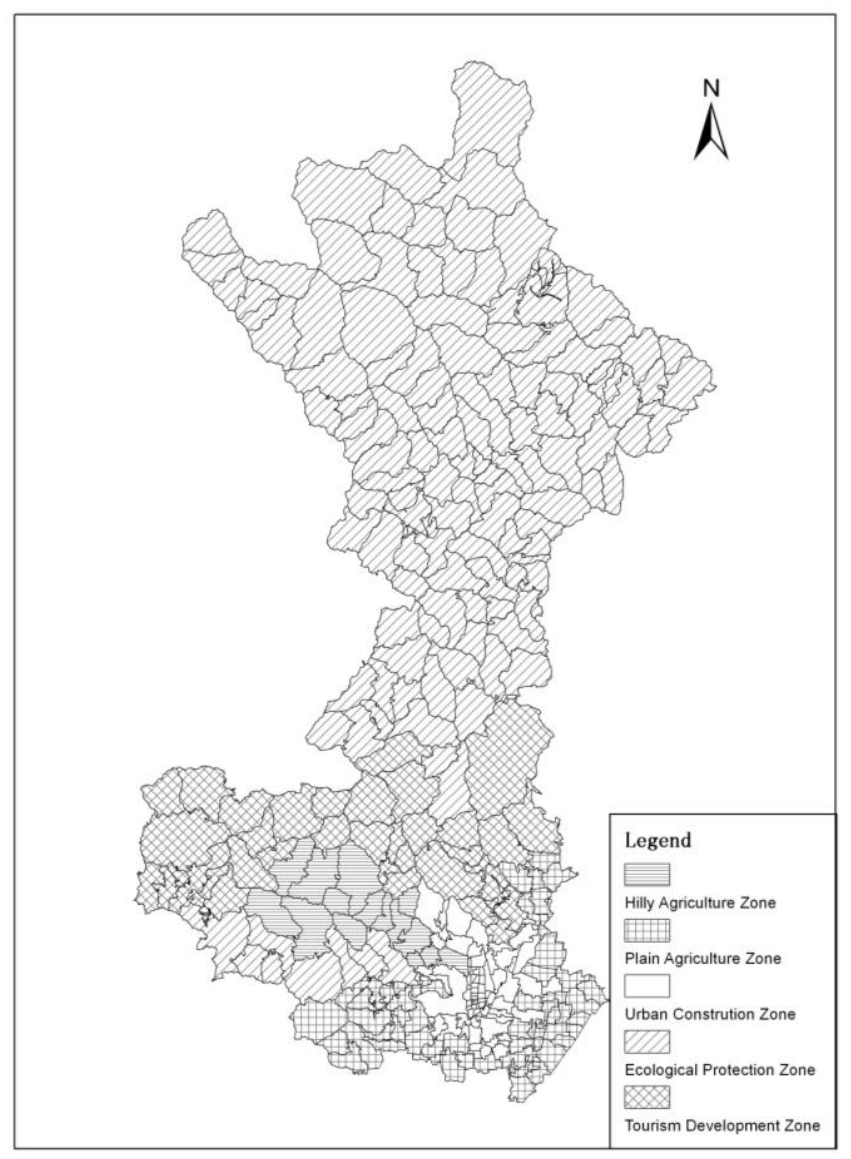

Fig. 2. Land rearrangement zoning in Huairou district

\section{RESULT OF LAND REARRANGEMENT ZONING}

Huairou district were divided into 5 land rearrangement zones, direction and key aspects of each land rearrangement zone was described as followed:

\section{A. Plain agriculture zone}

This zone includes Yangsong, Miaocheng, Beifang, Huairou, Qiaozi and south of Huaibei. It is an important area for producing grain, oilseed and vegetables.

The direction of land rearrangement in this zone is to construct modern high-efficiency agriculture and carry out rural construction land consolidation reasonably. Construction contents include constructing large-scale basic farmland, strengthening public finance support for the main grain production area and basic farmland conservation area as well as improving farmland infrastructure. In land circulation, scale land use could be realized to improve agricultural production efficiency. Prevention and treatment for farmland must be strengthened to improving environment of farmland and comprehensive grain production ability.

\section{B. Hilly agriculture zone}

This zone includes some villages in Jiuduhe, Bohai, Qiaozi. This area is advantageous to produce fruits for its good natural conditions. It is also an important area for chinese chestnut production.

The direction of land rearrangement in this zone is to carry out agriculture land consolidation completely and rural construction land consolidation orderly, using rural land by economizing intensive ways, doing the town planning well according to the request of constructing new rural and removing natural villages to make scattered peasant's house join together. In hilly agriculture zone, insuring the stability of agricultural production must be focused, meanwhile, agriculture land consolidation is the best way to dispel the limit of different terrain on agriculture production. Forestry and fruit industry could be developed based on advantages of this zone. Providing adequate construction land for necessary, supporting farm road and water conservancy facilities construction is necessary.

\section{Urban construction zone}

This zone includes Huairou, Qiaozi, Yanxi, Beifang, Miaocheng. It has much construction land, little farm land and unutilized land. There are some problems in land use such as extensive land using, irrational variety structure distribution. However, tidal flat resource is rich in this zone.

Land rearrangement contents include rural population are guided to concentrate in central area of urban and town, accepting land resource of this zone in urban planning administration system and forbidding to renovate or built an extension to the old house. In the meantime, scale of urban and industrial land should be stringently controlled while their structure and distribution should be optimized to realize the economical and intensiveness of land use.

\section{Ecological protection zone}

This zone includes Labagoumen, Changshaoying, Baoshan, Tanghekou, Liulimiao and some villages of Jiuduhe, Qiaozi, Qyanxi. This zone has much land especially forest land, it is suitable for forestry development based on good site condition for vegetation and porous, fertile soil. This zone has poor agricultural production condition, cultivated land is mainly dry land, and the cultivated land pieces are scattered which is bad to mechanized farming.

Land rearrangement contents here include strengthening forest construction, Implementing land rearrangement, barren hill afforestation and closed forest in areas with abundant precipitation. Implementing urban land consolidate to realize villages moving and ecological restoration, and supporting all types ecological construction projects to promote restoration and improvement of environment. Arable reserved land resources reclamation could be implemented reasonably to increase arable land as reserved land resources are rich in this zone. But it is extremely important to protect farmland especially arable land and strengthen the bond between all types ecological land.

\section{E. Tourism development zone}

This zone includes Jiuduhe, Bohai, Huaibei and some villages of Huairou, It is well-located and easy to access, and it has a lot of tourist spots and abundant forest fruits resources.

Tourism development would be taken as emphasis in this zone. In addition, building modern agricultural model of high quality fruits production and tour is important for promoting economic benefit in agricultural production and improving ecological environment. Agriculture land consolidation should also be implemented to realize the 
economical and intensiveness of land use.

\section{CONCLUSION}

a) This land rearrangement has confirmed main restrictive factors and target of land rearrangement in Huairou district, provided a basis for land rearrangement measures in different zones.

b) Overall implementing and arrangement for land rearrangement projects on the basis of land rearrangement zoning could give consideration to both natural and social economic conditions, it could also play a active role in land rearrangement, ensuring food safety or even social and economic development.

c) Comprehensive index value method was used in this study, it did not use method based on homogeneous region theory which was generally used in natural zoning, but putting the direction of land rearrangement, a function attribute, as the focus of zoning. Then, evaluated entire region with evaluate factors related to the direction of land rearrangement. This method is more suitable to regions that focus on function $f$ attribute.

\section{ACKNOWLEDGMENTS}

This research was supported by the Ministry of Land and Resources' Special Funds for Scientific Research on Public Causes (201211045).

\section{REFERENCES}

[1] [Zhengshan Ju, Ming Luo, Fengrong Zhang,Fei Xiao. "Developing trends of regional land consolidation in China," Transactions of the CSAE, Vol. 19, pp. 6-11, February 2003.

[2] Zhengfeng Zhang, Baiming Chen. "Land consolidation subzoning:a case study of Daxing district of Beijing", Transactions of the CSAE, Vol. 21, pp. 123-126, February 2005.

[3] Chuncheng Ma, Lingchao Wang. "A Research on Regionalization for Comprehensive Land Consolidation in Yiyang County," Scientific and Technological Management of Land and Resources, Vol. 28, pp. 56-60, June 2011.

[4] Cuijuan An, Cuiping Wang, Huali Hou. "Research on the regionalization and countermeasures of comprehensive treatment of Beijing land and resources". Territory \& Natural Resources Study, pp. 15-16, May 2010.

[5] Huan Wang. "Evolvement of Land Consolidation Partition Research". Anhui Agri. Sci. Bull, Vol. 17, pp. 149-153 November 2011.

[6] Haisheng Cai, Jianning Zhao, Yan Zeng, Meiqiu Chen. "Categorizing the Land Reconsolidation Zones in Jiangxi Province. China Land Science”. China Land Science, Vol. 25, pp. 38-44, 51, March 2011.

[7] Hongyan Feng, Yongzhong Tan, Qingri Wang, Jia Chen, Zhengguo Yu. :Review of the Research on Land Use Zoning in China". China Land Science, Vol. 24, pp. 71-76, August 2010.

[8] Mengli Xia. "Research on Regionalization of Land Reclamation in coal base of Henan province. Innovation Studies”. Innovation Studies. pp. 30-31, May 2010.

[9] Yuqi Lu, Kang Lin, Li Zhang. "The Methods of Spatial Development Regionalization:A Case Study of Yizhen City". Acta Geographica Sinica, Vol. 62, pp. 351-363, April 2007. 